\title{
The speciation of Australopithecus and Paranthropus was caused by introgression from the Gorilla lineage
}

Johan Nygren

2018

ABSTRACT: The discovery of Paranthropus deyiremeda in 3.3-3.5 million year old fossil sites in Afar (Haile-Selassie, 2015), together with 30\% of the gorilla genome showing lineage sorting between humans and chimpanzees (Scally, 2012), and a NUMT ("nuclear mitochondrial DNA segment") that is shared by both gorillas, humans and chimpanzees, and that dates back to 6 million years ago (Popadin, 2017), is conclusive evidence that introgression from the gorilla lineage caused the speciation of both the Australopithecus lineage and the Paranthropus lineage, providing a lens into the gorilla-like features within Paranthropus, as well as traits within Homo that originate from the gorilla branch, such as a high opposable thumb index (Almécija, 2015), an adducted great toe (Tocheri, 2011; McHenry, 2006), and large deposits of subcutaneous fat.

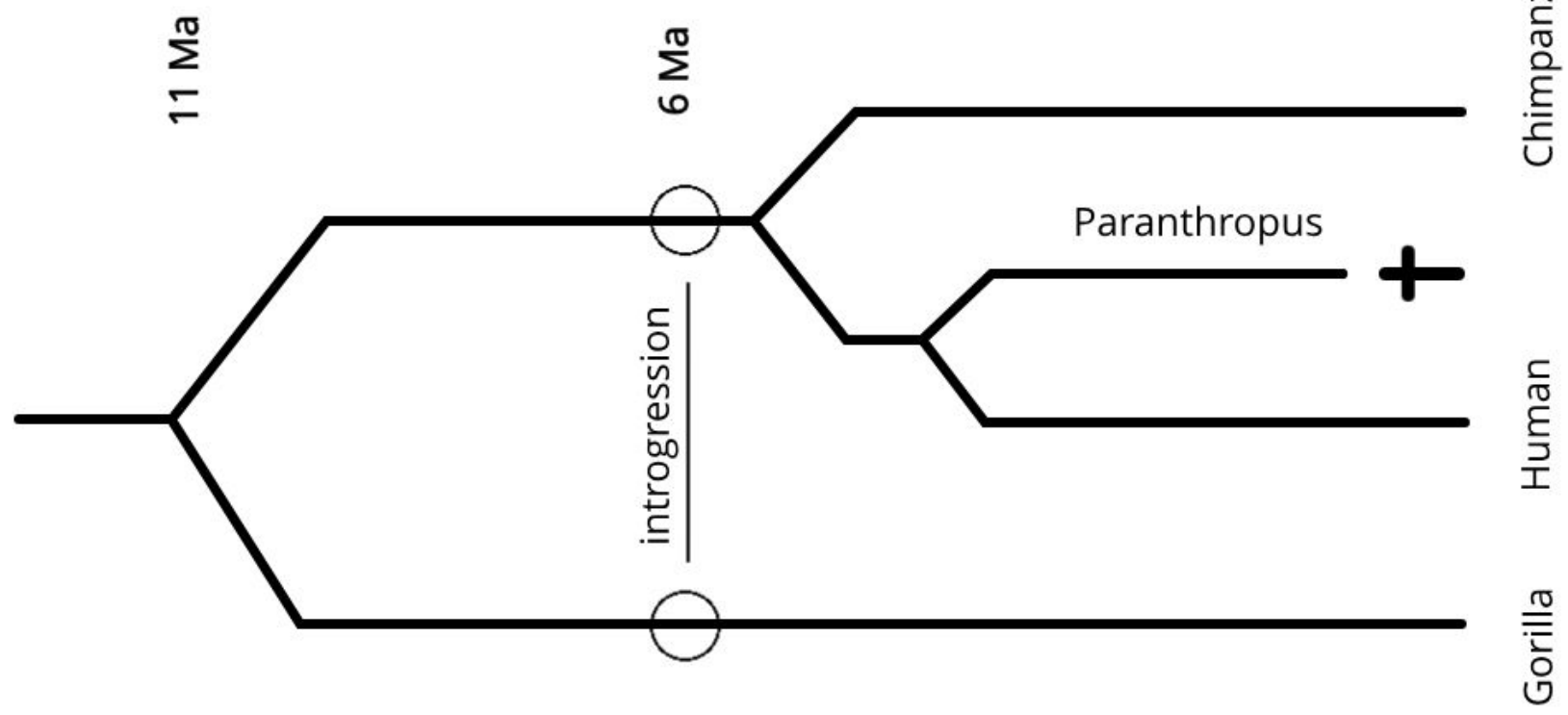

Fig. 1. Phylogenetic tree showing how introgression caused the speciation of humans. This introgression speciation model predicts an early split for Paranthropus and Australopithecus, increasingly shown in the fossil record (Haile-Selassie, 2015, 2016; Wood, 2016), and also shows that the evolution of genes that ended up in Australopithecus, and therefore in extant humans, as well as in Paranthropus, can and should be traced along the gorilla lineage as well. 


\section{The introgression speciation model and a revised phylogenetic tree}

The origin of our species has increasingly been discovered over the past century, through Darwin to the discovery of DNA and the double-helix, to Lucy and fossils of Australopithecines that originate from the Afar region in Ethiopia from the Pliocene. The genetic data from Scally in 2012, and Popadin in 2017, now provides conclusive evidence for how Paranthropus and Australopithecus, as two separate lineages, both speciated as a result of introgression from the gorilla lineage (Fig. 1). That introgression fills in the "missing link" and shows how the origin of our species is not one single continuous lineage, but the hybridization of both the gorilla lineage and the common ancestor of humans and chimpanzees, an event that occurred in the late Miocene. The introgression speciation model (Fig. 1) predicts an early split between the Paranthropus lineage and the Australopithecus lineage.

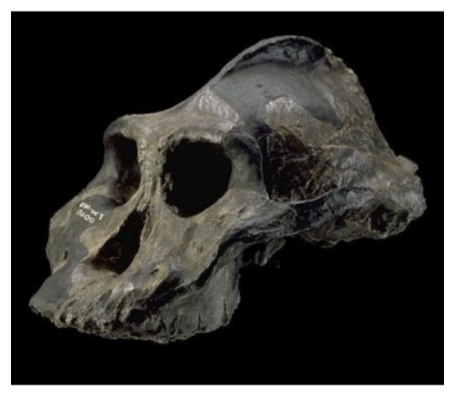

Paranthropus aethiopicus 2.8-2.3 Ma

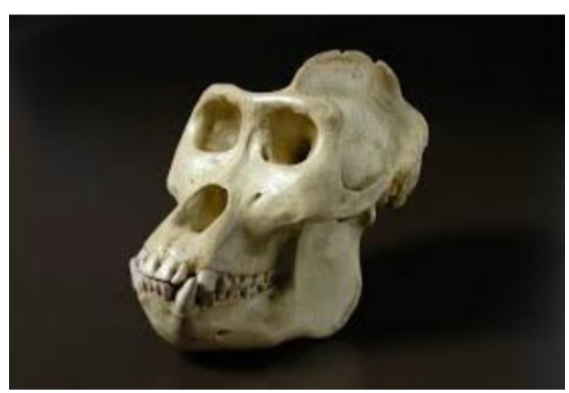

Gorilla gorilla

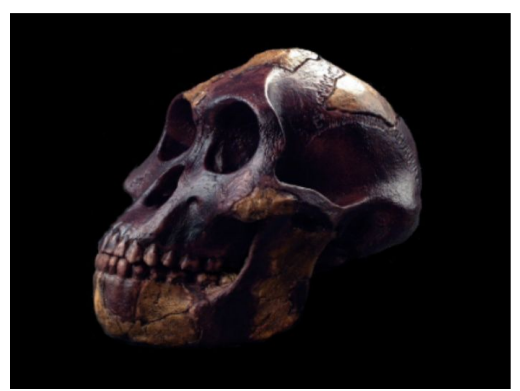

Australopithecus afarensis 3.7-2.9 Ma

Fig2. Introgression from Gorilla caused the speciation of both Australopithecus and Paranthropus, and means that traits that have evolved independently in the gorilla lineage were transferred into the hybrid lineages. Paranthropus are often described as "gorilla-like", they have sagittal crests which suggest strong muscles of mastication, and broad, grinding herbivorous teeth, that led to the name "nutcracker man" for Paranthropus boisei who lived between 2.4-1.4 Ma.

\section{The Burtele foot (BRT-VP-2/73) and Au. deyiremeda, a Paranthropus?}

With conclusive evidence of an introgression speciation model, it is apparent that the Paranthropus and Australopithecus lineages both speciated as a result of introgression from Gorilla (Fig. 2), and that the two lineages separated as early as 5-6 Ma, adapting to separate niches. The discovery of 3.2-3.5 million year old hominin fossils that show divergent evolution from Au. afarensis from the same time period (Haile-Selassie, 2012, 2015), featuring an abductable great toe (Fig. 3) instead of the human-like hallux of Au. afarensis, a human-like transverse arch that stiffens the foot (Haile-Selassie, 2012), instead of the transitional arch of $A u$. afarensis that is in-between Homo and Pan, and jaws and teeth that shares characteristics with Paranthropus and Homo (Haile-Selassie, 2015) suggested the classification of a new species Australopithecus deyiremeda, meaning "close relative" in the local Afar language. 
The introgression speciation models shows that $A u$. deyiremeda is better classified as a Paranthropus, $P$. deyiremeda, and that an early split between Paranthropus and Australopithecus is the reason there were two separate lineages of hominins during the Pliocene (Haile-Selassie, 2015, 2016; Wood, 2016), clearly distinguishable by their locomotor adaptation and diet.

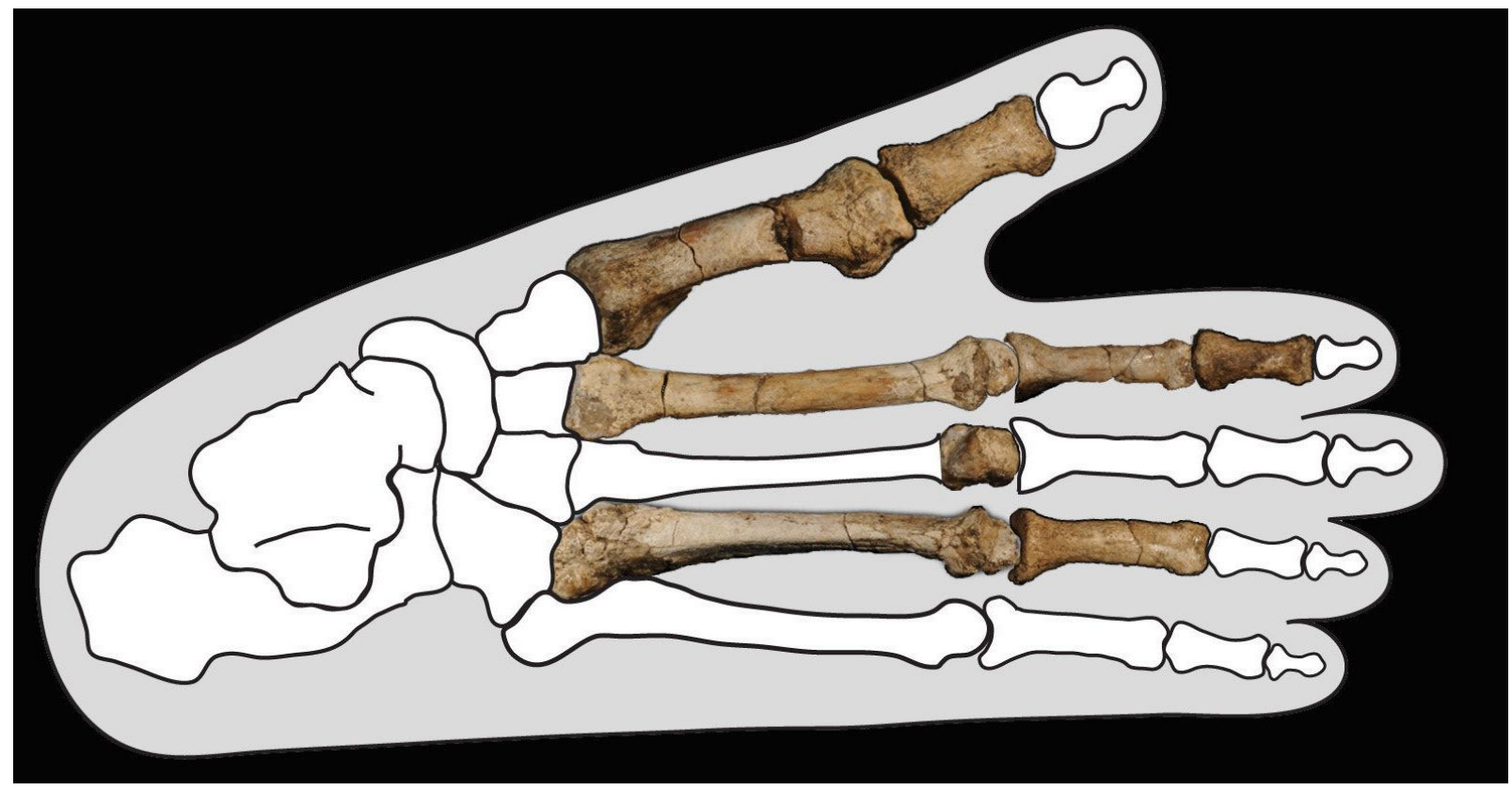

Fig 3. The Burtele foot, BRT-VP-2/73, found in 2009 (Haile-Selassie, 2015) in Burtele at Woranso-Mille, Afar, tentatively assigned Au. deyiremeda (Haile-Selassie, 2015), contemporaneous with Au. afarensis, shows distinct locomotor adaptation as it retains a grasping hallux, in contrast to the human-like foot that had developed in Australopithecus afarensis. The conclusive evidence of an introgression speciation model suggests that deyiremeda is better classified as Paranthropus deyiremeda, and that it provides a fossil record that support an early split for Paranthropus and Australopithecus, two lineages that adapted for separate niches.

\section{The classification of Paranthropus deyiremeda, an overview}

The classification of $P$. deyiremeda within this thesis has its foundation within the genetic data for an introgression speciation model (Fig. 1), originally the Gorilla Genome Project (Scally, 2012), which shows without a doubt that there was introgression of $30 \%$ of the Gorilla genome into the human-chimpanzee lineage (the common ancestor of Pan/Homo. ) The introgression event, which can be dated from the NUMT on chromosome 5 to $4.5 \mathrm{Myr}$ after the Gorilla/Pan-Homo split, to around $6 \mathrm{Ma}$, (Popadin, 2017), which is the time of the Pan-Homo split, is a boundary for the earliest split between Paranthropus and Australopithecus. Traits within Paranthropus that resemble Gorilla, such as the sagittal crest, are more parsimonious as a result of the introgression event rather than convergent evolution, and lineage sorting similar to the $30 \%$ of the Gorilla genome that displays lineage sorting with Pan and Homo (Scally, 2012), which supports the hypothesis of Paranthropus as a lineage that also speciated from the introgression. 


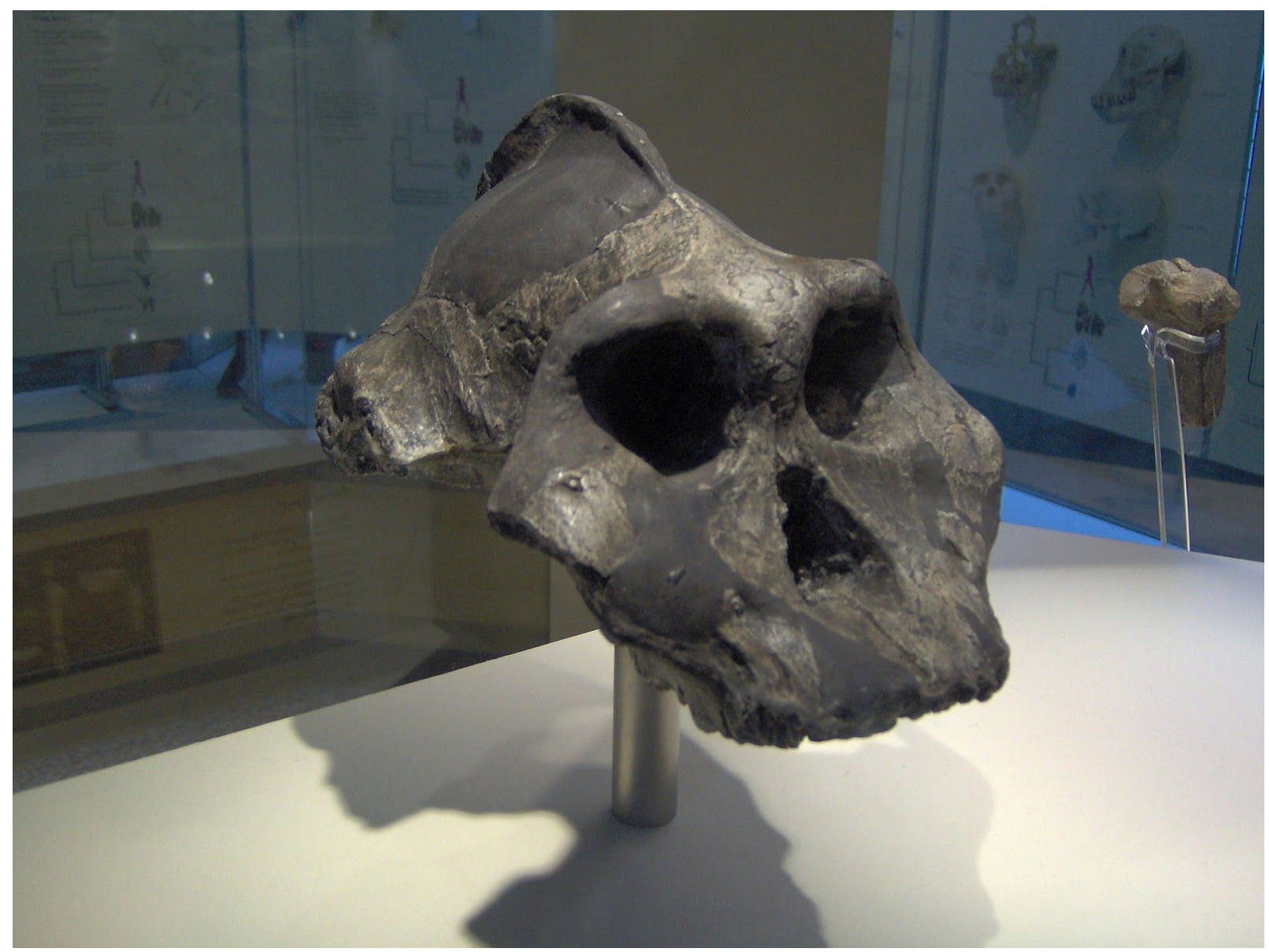

Fig. 4. Paranthropus aethiopicus, 2.8-2.3 Ma, with gorilla-like sagittal cranial crests as an attachment for strong muscles of mastication, a dietary adaptation. The genetic proof of an introgression event at the time of the Pan-Homo spit shows that the most parsimonious origin for those features within Paranthropus was lineage sorting from the introgression event, originating in Gorilla, rather than convergent evolution. Image from public domain (CC BY-SA 3.0).

The foot stiffness in Paranthropus deyiremeda (Haile-Selassie, 2012) is not a preserved character, it is a derived character that is absent in the Au. afarensis lineage as well as in Pan and Gorilla, and that exists together with an abducted great toe, and is contemporary with an adducted (human-like) hallux as a derived feature in Au. afarensis, undisputable data for that deyiremeda is a separate lineage that had adapted for a separate niche, which is also what justified its original classification as a "close relative" (Haile-Selassie, 2015). The denthognathic features that are similar to Paranthropus (Haile-Selassie, 2015) suggest similar dietary adaptations, and within the hypothesis of introgression as a cause of speciation, the most parsimonious explanation is lineage sorting from the introgression event, with adaptations for browsing such as large muscles of mastication that were co-opted for grazing. (Cerling, 2017) 


\section{Introgression from Gorilla seen in lineage sorting between humans and chimpanzees}

The past two decades have seen rapid advances in whole genome sequencing, with the Human Genome Project completed in 2003 (Venter, 2003), the chimpanzee genome two years later (Waterson, 2005) and the Gorilla genome in the following decade (Scally, 2012). The whole genome sequencing of Gorilla gave the first clues to an introgression speciation model, and showed that $30 \%$ of the gorilla genome exhibits lineage sorting with the human genome and chimpanzee genome (Scally, 2012), 15\% of the gorilla genome is closer to Homo than to Pan, and another $15 \%$ closer to Pan than to Homo, a result of gene transfer from Gorilla in the introgression event that also transferred the NUMT on chromosome 5 (Popadin, 2017) to all three lineages.

\section{The NUMT on chromosome 5 as conclusive evidence of an introgression speciation model}

Mitochondria is inherited separately from nuclear DNA, and fragments of mitochondrial DNA are known to get inserted into nuclear DNA to form NUMTs, i.e. nuclear pseudogenes of the mtDNA. There is a NUMT sequence on chromosome 5 shared by gorillas, chimpanzees, and humans, shown from mutation rates to date back to 6 million years ago, a result of interbreeding between lineages that had diverged as much as $\sim 4.5 \mathrm{Myr}$ prior to the interbreeding event (Popadin, 2017) (Fig. 5), which fits with the Gorilla/Pan-Homo split at 11Ma. The NUMT on chromosome 5 shares affinities with the gorilla lineage mtDNA (Popadin, 2017) suggesting that it originates from the gorilla lineage.

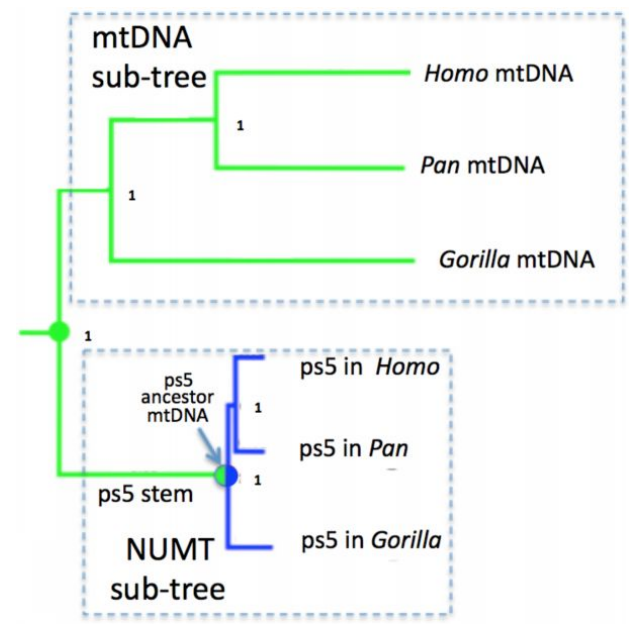

Fig 5. NUMT on chromosome 5 shared by Gorilla, Pan and Homo, that had diverged 4.5Myr prior to the introgression event, which fits the estimate for when the Gorilla lineage split from the common ancestor of Pan and Homo around 11 million years ago. Image from Popadin et al, 2017. 


\section{The introgression speciation model and the Pthirus host switch 3.3 million years ago}

The evolutionary history of anthropoid primate lice includes a host switch from the gorilla lineage to Homo around 3.3 million years ago (Reed, 2007) (Fig. 6). The introgression speciation model supports the idea of Paranthropus as an intermediary in the host switch, and that Paranthropus, which shares ancestral features such as a cone shaped rib cage, abducted great toes, and similar diet as Gorilla (Cerling, 2011), may have continued to mate with both Gorilla and Australopithecus up to the Pthirus split 3.3 Ma, while Australopithecus were sexually isolated from Gorilla. (Fig. 7)

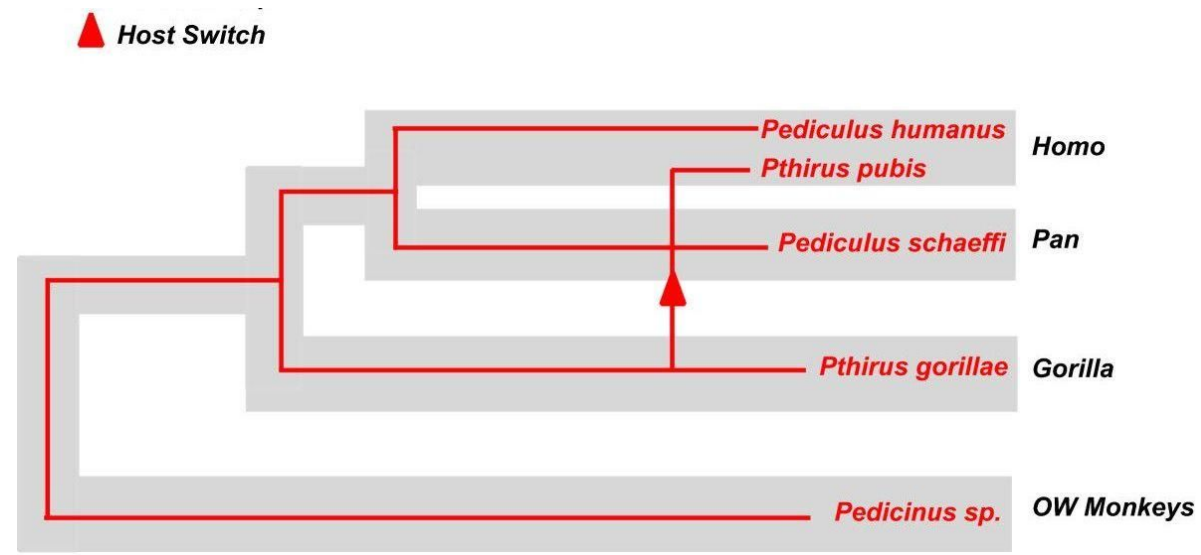

Fig 6. Reconstruction showing perfect cospeciation between with hosts and parasites with the exception of a single host switch of Pthirus sp. from gorillas to humans (marked by an arrow). Image from Reed et al, 2007.

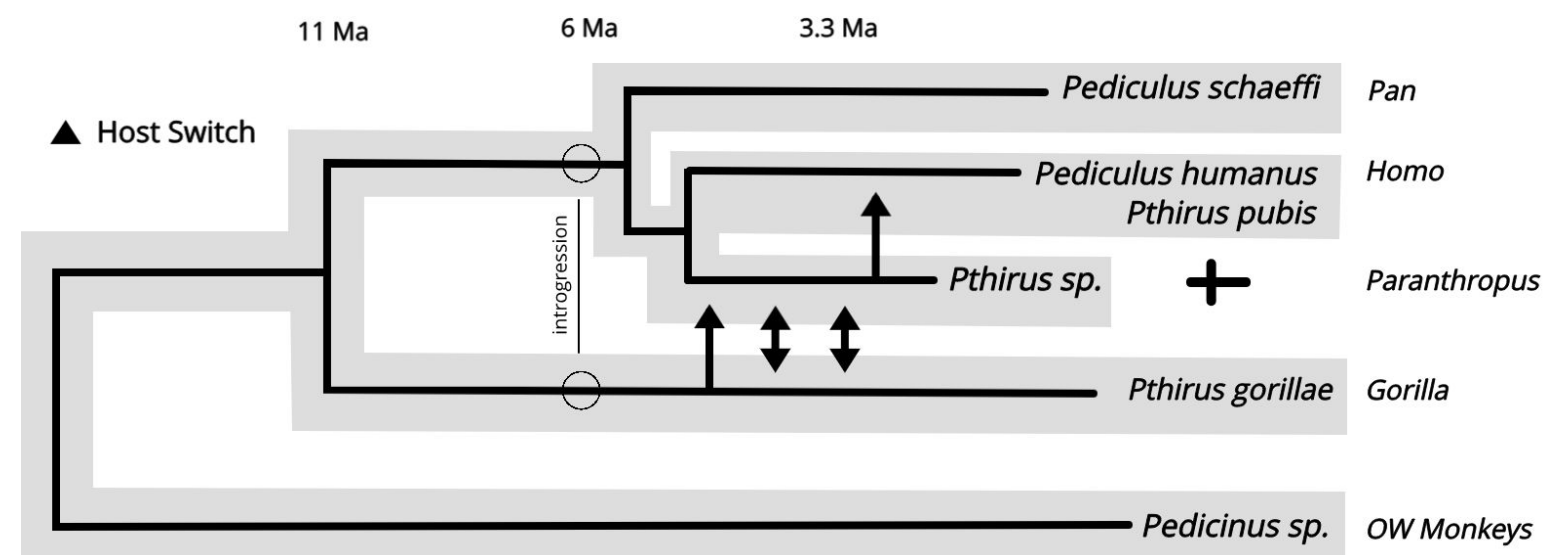

Fig 7. Coevolutionary reconstruction of primate lice and their hosts, with Paranthropus as an intermediary in the Pthirus host switch, a scenario where Paranthropus and Gorilla continued to mate up to 3.3 Ma. 


\section{References}

Almécija, S., Smaers, J. B., \& Jungers, W. L. (2015). The evolution of human and ape hand proportions. Nature Communications, 6(1). https://doi.org/10.1038/ncomms8717

Cerling, T. E., Mbua, E., Kirera, F. M., Manthi, F. K., Grine, F. E., Leakey, M. G., ... Uno, K. T. (2011). Diet of Paranthropus boisei in the early Pleistocene of East Africa. Proceedings of the National Academy of Sciences, 108(23), 9337-9341. https://doi.org/10.1073/pnas.1104627108

Haile-Selassie, Y., Saylor, B. Z., Deino, A., Levin, N. E., Alene, M., \& Latimer, B. M. (2012). A new hominin foot from Ethiopia shows multiple Pliocene bipedal adaptations. Nature, 483(7391), 565-569.

https://doi.org/10.1038/nature10922

Haile-Selassie, Y., Gibert, L., Melillo, S. M., Ryan, T. M., Alene, M., Deino, A., ... Saylor, B. Z. (2015). New species from Ethiopia further expands Middle Pliocene hominin diversity. Nature, 521(7553), 483-488.

https://doi.org/10.1038/nature14448

Haile-Selassie, Y., Melillo, S. M., \& Su, D. F. (2016). The Pliocene hominin diversity conundrum: Do more fossils mean less clarity? Proceedings of the National Academy of Sciences, 113(23), 6364-6371.

https://doi.org/10.1073/pnas.1521266113

McHenry, H. M., \& Jones, A. L. (2006). Hallucial convergence in early hominids. Journal of Human Evolution, 50(5), 534-539. https://doi.org/10.1016/i.jhevol.2005.12.008

Popadin, K., Gunbin, K., Peshkin, L., Annis, S., Fleischmann, Z., Kraytsberg, G., ... Khrapko, K. (2017, May 9). Mitochondrial pseudogenes suggest repeated inter-species hybridization in hominid evolution. Cold Spring Harbor Laboratory. https://doi.org/10.1101/134502

Reed, D. L., Light, J. E., Allen, J. M., \& Kirchman, J. J. (2007). Pair of lice lost or parasites regained: the evolutionary history of anthropoid primate lice. BMC Biology, 5(1), 7. https://doi.org/10.1186/1741-7007-5-7

Scally, A., Dutheil, J. Y., Hillier, L. W., Jordan, G. E., Goodhead, I., Herrero, J., ... Durbin, R. (2012). Insights into hominid evolution from the gorilla genome sequence. Nature, 483(7388), 169-175.

https://doi.org/10.1038/nature10842

Tocheri, M. W., Solhan, C. R., Orr, C. M., Femiani, J., Frohlich, B., Groves, C. P., ... Jungers, W. L. (2011). Ecological divergence and medial cuneiform morphology in gorillas. Journal of Human Evolution, 60(2), 171-184. https://doi.org/10.1016/j.jhevol.2010.09.002

Venter, J. C., Adams, M. D., Myers, E. W., Li, P. W., Mural, R. J., Sutton, G. G., ... Zhu, X. (2001). The Sequence of the Human Genome. Science, 291(5507), 1304-1351. https://doi.org/10.1126/science.1058040

Waterson, RH. (2005). Initial sequence of the chimpanzee genome and comparison with the human genome. Nature, 437(7055), 69-87. https://doi.org/10.1038/nature04072

Wood, B., \& K. Boyle, E. (2016). Hominin taxic diversity: Fact or fantasy? American Journal of Physical Anthropology, 159, 37-78. https://doi.org/10.1002/ajpa.22902 